\title{
Iconicity and Viewpoint in Determining Word Order in Japanese Dative Construction
}

\author{
NORIKO IWASAKI and MISUMI SADLER \\ University of California, Davis and University of Illinois, Urbana-Champaign
}

\section{Introduction}

The alternation in word orders in dative clauses has been discussed in various languages from numerous perspectives (e.g. Bresnan and Nikitina 2003; Givón 1984; Thompson 1990, 1995). In English, for example, there are two possible orderings of ditransitive clauses as in (1):

(1) a. Laura gave Nim a bagel.

b. Laura gave a bagel to Nim. (Thompson 1995: 156)

While some linguists in earlier work consider this alternation, which is often referred to as "dative shift," to be an optional movement, recently a number of scholars have pointed out some semantic, discourse-pragmatic and cognitive factors that influence this alternation, such as: context, animacy, referentiality, topicality, accessibility and weight or heaviness of NPs (e.g. Collins 1995; Givón 1984; Smyth, et al. 1979; Thompson and Koide 1987; Thompson 1990, 1995; Wierzbicka 1986).

Japanese also has three-argument dative clauses which have at least two possible orderings: goal-patient or patient-goal as demonstrated in (2):
a. Taroo-ga
Hanako-n
nimotu-o okut-ta.
$-\mathrm{NOM}$
-DAT
package-ACC
b. Taroo-ga
nimotu-o
Hanako-ni
send-PAST
- NOM
$-\mathrm{ACC}$
-DAT send-PAST

'Taro sent Hanako a package.' (Miyagawa and Tsujioka 2004: 5)

Japanese is said to be a free word order language. In dative clauses, goal is generally marked with the particle $n i$, and patient is marked with the particle $o$. It is generally assumed that the goal-patient order as in (2a) is the canonical order, and patient-goal as in (2b) is derived by optional scrambling (e.g. Hoji 1985; 
Yatsushiro 2003). However, some argue that these two orderings are basegenerated (e.g., Miyagawa 1997). Miyagawa and Tsujioka (2004) further proposed that permutations happens only when goal is locative (as in Taroo-ga Tokyo-ni nimotu-o okutta 'Taro sent a package to Tokyo' p. 9), and that it is irrelevant when goal is possessive (e.g. Taro-ga Hanako-ni nimotu-o okutta 'Taro sent Hanako a package' p. 9). They claim that these two instances have distinct structures: the goal being a PP in the former, and a DP in the latter.

In the current study, we assume the standard analysis: that these two orderings are permutations of one structure. This is unlike the English dative shift, which unarguably involves two distinct structures. Moreover, the previous literature suggests that these two orderings of NPs in Japanese are not motivated by semantic factors. Thus, examining Japanese dative clauses possibly provides us with an opportunity to reveal the relation between word order and cognitive factors without the confounding factor of obvious structural or semantic differences. Hence, we examine both spoken and written corpora and discuss the role of iconicity and viewpoint that potentially affect the orderings of goal and patient.

\section{Iconicity and Viewpoint}

Some linguists contend that language mirrors the human conceptual system in that there is an isomorphic relation between the serial order of words or clauses expressed in language and the order in which entities in the event are perceived in the real world (e.g., DeLancey 1981, Givón 1995, Haiman 1980).

DeLancey (1981) proposes that split case-marking and verb-agreement patterns in some languages can be explained by the notions of iconicity ('attention flow' in DeLancey) and viewpoint. According to DeLancey, iconicity or attention flow "determines the linear order of NPs," and "[t]he NPs in a sentence are presented in the order in which the speaker wishes the hearer to attend to them" (p. 632). In the case of dative clauses, the most prototypical and common pattern is from agent to patient as in (3a):

(3) a. She gave me a check.

b. I got a check from her. (DeLancey 1981: 638)

(3a) is iconic in that it matches the natural attention flow from the giver/source of an event, she, who is the natural starting point, to the receiver/goal, me. (3b), on the other hand, is not iconic since the receiver/goal is selected as the agent of the sentence rather than the giver/source. According to DeLancey (1981), non-iconic sentences like (3b) are highly marked in many languages, and the existence of such patterns can be attributed to the notion of viewpoint, or "the perspective from which the speaker describes the event" (p. 626). The non-iconic sentence (3b) exhibits the prototypical viewpoint in that 'the receiver/goal,' $I$, is chosen to be the viewpoint as the "natural locus of viewpoint" (DeLancey 1981: 639). 
What determines "inherent eligibility for viewpoint status" (DeLancey 1981: 639) of NPs in dative clauses may be associated with their 'topic-worthiness' (Thompson 1990, 1995) in discourse. Topic-worthiness is defined as "a cluster of properties which influence the packaging of information in languages of the world, specifically to the likelihood of a noun phrase being the topic of discussion" (Thompson 1995: 158). Topic-worthiness can be measured by the animacy, heaviness/length, referentiality and accessibility of NPs. Considering such properties, Thompson $(1990,1995)$, for example, account for the dative shift in English.

The notion of iconicity and viewpoint, which may be associated with topicworthiness, may also explain the alternation in the word order of Japanese dative constructions. In the study of acquisition of children learning Japanese as their first language, iconicity was found to affect Japanese children's word order preference of dative sentences. Although goal-patient order is considered to be the canonical order in Japanese, Suzuki et al. (1999) found that Japanese children preferred iconic patient-goal word order both in comprehension and production tasks. ${ }^{1}$ The patient-goal word order is iconic in that the entity to be transferred is expressed before the destination of the transfer; it is iconic to the event both in spatial and temporal senses. The same effect of iconicity was also found among Korean children (Cho et al. 2002).

Kawano (2004) examined the orders of NPs that co-occur with verbs of spatial expressions and found that the NP-o NP-ni order was more frequent than the NP$n i \mathrm{NP}-o$ order when verbs refer to events in which patient moves between source and goal such as utusu 'move' and hakobu 'carry' in a corpus of newspaper articles. She attributed this to iconicity (i.e., the order of perception of the patient and goal in the event). These verbs are similar to verbs in dative clauses in the sense that source and goal are involved.

Previous literature examined some discourse-pragmatic factors that may affect the orderings of NPs in Japanese dative clauses. Yamashita (2002) examined a total of 2,635 sentences in magazine articles and found 19 non-canonical word order sentences among which were six instances of patient-goal dative clauses (i.e., patient NP is scrambled to the position before goal). She found that the prominent characteristics of scrambled NPs in the non-canonical word order sentences were that they were heavy as shown in (4a), and that they made reference to preceding contexts as shown in (4b).

\footnotetext{
${ }^{1}$ Sugisaki and Isobe's (2001) findings were inconsistent with those of Suzuki, et al. Japanese children in their study had more difficulty in comprehending the patient-goal than the goal-patient order sentences.
} 
(4) a. (from Seiji Kuroi, 'Kenzaburo Oe and the Nobel prize')

Nooberusyoo-no zyusyoo-wa, [[Oe Kenzaburoo-si-no

Nobel Prize-GEN receiving-TOP Oe Kenzaburo-Mr.-GEN

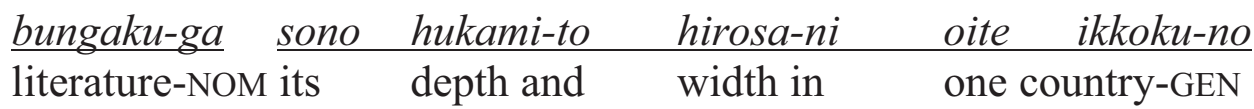

iki-o koeru mono de aru koto]]-o sekai-ni meezi-sita.

range-ACC exceed thing COP fact-ACC world-DAT showed

'[Mr. Oe's] receiving of the Nobel prize clearly demonstrated to the world that Mr. Oe Kenzaburo's literature exceeds, in its depth and width, the [standard of] one country.' (Yamashita 2002: 605)

b. (from 'Men of My Type'; the speaker is a model, talking about Robin Williams)

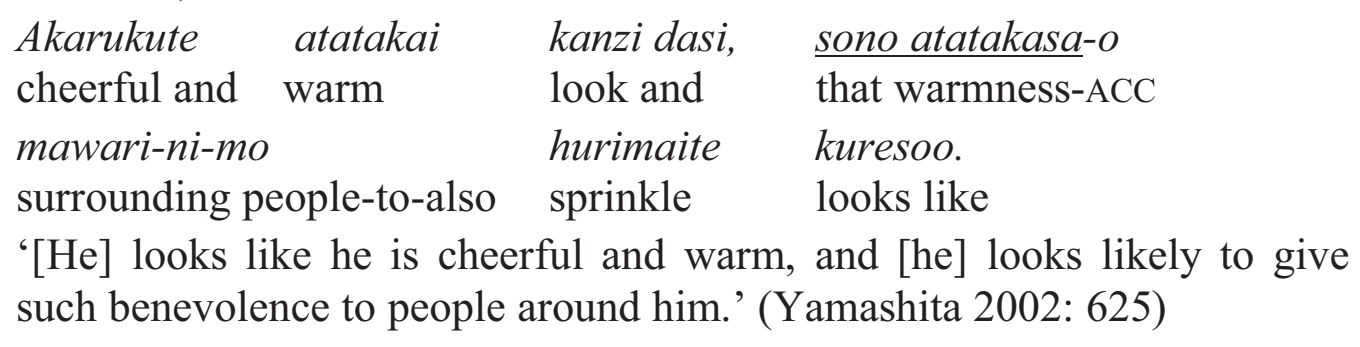

Although referentiality was one of the characteristics of scrambled constituents, Yamashita (2002) found that only seven of 19 scrambled constituents represented given information. Ferreira and Yoshita (2003) found given-new effects in subjects' production of dative sentences in their psycholinguistics experiment utilizing a spoken recall task, but they attributed the effects to the efficiency in spoken production rather than to cognitive factors. They suggested that speakers position a mentioned or activated argument earlier due to its availability.

Another psycholinguistic study, Yamashita et al. (2003), found that Japanese preferred to produce sentences of the same thematic order as the ones they just produced, regardless of animacy status of the NPs.

The current study examines naturally occurring conversation and modern Japanese novels to shed light on the role of iconicity and viewpoint (i.e., factors contributing to topic-worthiness: animacy; heaviness/length; referentiality; accessibility) in the orderings of NPs.

\section{Data and Methodology}

There are two sets of data used for the present study. The conversational data consists of 26 transcripts of audio taped casual conversations (Aoki et al. to appear). The transcripts consist of single-sex and mixed-sex conversations with two to five participants; each conversation is 3 to 18 minutes long. The total amount of data used is approximately 150 minutes long and 278 pages of transcripts (approximately 5000 clauses). The speakers are 15 to 50 years old and 
use standard Japanese. The relationships between the speakers are mostly friends, couples or family, and the recordings took place in private homes or restaurants either in Japan or in the U.S. during the 1990s.

The written data consists of four modern Japanese novels in an existing modern Japanese literature corpus, Shinchosha no zeppan 100-satsu. [100 out-ofprint books from Shinchosha Publisher] CD-ROM (2000). ${ }^{2}$ The first two authors are male and the other two are female. Approximately 3150 pages, 6300 clauses in total, are examined. All the clauses are divided into two: the narrative portion and the conversational portion.

We selected seven verbs in (5) that possess the prototypical semantics of ditransitive verbs and that take two goal positions (location and recipient), in keeping with Miyagawa and Tsujioka (2004) in order to examine the occurrences of both location and recipient as goal. ${ }^{3}$

$$
\begin{array}{ll}
\text { ageru 'give' okuru 'send' } & \text { kaesu 'return' } \\
\text { ataeru 'give' azukeru 'entrust' } & \text { todokeru 'deliver' dasu 'send' }
\end{array}
$$

We excluded the following clauses from the analysis: relative clauses, whose heads are either patient or goal; passive clauses; topicalized clauses; clauses which contain -te morau, and fixed clauses such as kuti ni dasu 'to express.'

As soon as we started to examine the data, we encountered difficulty distinguishing between location and recipient. This may be because there is a parallelism between a motion event such as shown in (6a) and an event which involves three arguments as in (6b) and (6c) (DeLancey, 1981).

$$
\begin{array}{lcll}
\text { a. Ken-ga } & \text { Tookyoo-ni } & \text { it-ta. } & \\
\text {-NOM } & \text {-LOC } & \text { go-PAST } & \\
\text { 'Ken went to Tokyo.' } & & \\
\text { b. Ken-ga } & \text { Miki-ni } & \text { hana-o } & \text { okut-ta. } \\
\text {-NOM } & \text {-DAT } & \text {-ACC } & \text { send-PAST } \\
\text { c. Ken-ga } & \text { hana-o } & \text { Miki-ni } & \text { okut-ta. } \\
\text {-NOM } & \text {-ACC } & \text {-DAT } & \text { send-PAST }
\end{array}
$$

'Ken sent flowers to Miki.'

(constructed)

In Japanese, both locations and recipients are marked with the particle ni. This particle is characterized to be a "lexically complex grammatical morpheme" (Kabata 2000) due to its wide range of semantic and grammatical roles in discourse. In (6a), for example, ni marks the location 'Tokyo,' and in (6b) and

\footnotetext{
${ }^{2}$ We examined the following novels: Geta no ue no tamago by Hisashi Inoue, Shatei by Yasushi Inoue, Shokutaku no nai uchi by Fumiko Enchi and Jiuta by Sawako Ariyoshi.

${ }^{3}$ Miyagawa and Tsujioka claimed that it was possible for these verbs to occur with both recipient and locative goals, but we did not observe any such instances in our data. Note also that we excluded the verb kakeru 'ring' from our analysis since it is often used as a collocation, taking denwa 'telephone' in its patient position (as in denwa o kakeru).
} 
(6c), the same particle appears with the recipient of flowers, Miki. In terms of syntactic status, it is not entirely clear whether a given $n i$ is a dative case marker or locative postposition. Using syntactic tests, Sadakane and Koizumi (1995) suggested that $n i$ following goal NPs in dative causes is a dative case marker; however, the current authors' judgment to the syntactic tests is that they are variable depending on the verb and NPs.

While some NPs are more locative-like or recipient-like, we encountered some difficulty coding NPs in our data. For example, although a place name is typically identified as a location in a prototypical motion event such as shown in (6a), in three-argument clauses like (7a) and (7b), it is not easy to determine whether Tokyo refers to a location or a recipient (who is in Tokyo).
a. Ken-ga
Tookyoo-ni
nimotu-o
okut-ta.
-NOM
-LOC/DAT(?)
$-\mathrm{ACC}$
send-PAST
b. Ken-ga
nimotu-o
Tokyo-ni
okut-ta.
$-\mathrm{NOM}$
$-\mathrm{ACC}$
-LOC/DAT(?)
send-PAST
'Ken sent a package to Tokyo.'
(constructed)

The identification of categories becomes even more difficult when a terminal point is not a place name as seen in (8).

(8)
a. Ken-ga
byooin-ni
hana-o
okut-ta.
$-\mathrm{NOM}$
-LOC/DAT(?)
$-\mathrm{ACC}$
send-PAST
b. Ken-ga
hana-o
byooin-ni
okut-ta.
$-\mathrm{NOM}$
$-\mathrm{ACC}$
-LOC/DAT(?)
send-PAST

'Ken sent flowers to the hospital.'

Due to this difficulty, we will use the term GOAL to indicate both location and recipient as the terminal point of an event in three-argument clauses.

In order to explore how viewpoint determines the orderings of NPs, we examined goal and patient NPs in terms of properties associated with topicworthiness: referentiality, animacy, heaviness, and information accessibility. The coding schemes in (9) are used for the current study:
Coding Schemes for NPs
Referentiality: Referential or Non-referential
Animacy: Animate or Inanimate
Heaviness: Heavy (NP with modifiers) or Not heavy (NP without modifiers)


Information Accessibility: Given, Inferable, or New

- Given (when a referent is lexically given in the preceding context, or is present as an interlocutor as in the cases of NPs such as you and $I$ )

- Inferable (when a referent is inferable from previous discourse or its previous mention is rather distant)

- New (when a referent is newly introduced)

In examples (10) taken from the narrative portions of our written data, the goal NPs are double-underlined, and the patient NPs are single-underlined. (10a) shows the canonical dative construction in which the goal is expressed before the patient. Under our coding schemes, the goal, zyakusya no mikataosuru Tamajiroo 'Tamajiro, who supported the weak,' is identified as referential, animate, heavy, and given. The patient, kassai 'cheers,' is no-referential, inanimate, not heavy, and new. (10b), on the other hand, is an instance of a non-canonical construction where the patient, 'Yumiko' (=referential; animate; not heavy; inferable from the previous context) precedes the goal, 'hospital' (=non-referential; inanimate; not heavy; given).

(10) a. (from Sawako Ariyoshi, "Jiuta")

zyakusya-no mikataosuru Tamajiroo-ni

the weak-GEN support -GOAL

seken-wa kassai-o okutte-ita

people-TOP cheers-ACC send-PROG:PAST

'People had sent cheers to Tamajiro, who supported the weak'

b. (from Fumiko Enchi, "Shokutaku no nai uchi")
Yumiko-o
byooin- $n i$
azukeru
kotonishi-ta ...
-ACC hospital-GOAL entrust
decide on-PAST
'(that he) decided on leaving Yumiko in hospital's care'

\section{Findings}

\subsection{Overall Distribution}

There were 13 dative clauses out of 5000 clauses in the conversation data, and 97 dative clauses out of 6300 clauses in the written data. The low frequency in the spoken data is not surprising considering the fact that three-argument verbs are extremely rare in conversational English as well (Thompson 1990).

Because Japanese is a pro-drop language, any arguments that can be inferred from the context can be non-overt. Regardless of whether data are written or spoken, among the three arguments in dative clauses, agent is most frequently left unstated, followed by goal and patient as illustrated in (11). 


$$
\text { Conversation: Agent } 92.3 \%>\text { Goal } 84.6 \%>\text { Patient } 7.7 \%
$$

$(12 / 13)$

$(11 / 13)$

Written: $\quad$ Agent $62 \%>$ Goal $39 \%>$ Patient $12 \%$ $(58 / 93) \quad(38 / 97) \quad(12 / 97)^{4}$

Given the fact that non-overt arguments may be the equivalents of pronouns and that pronouns are considered to be more topic-worthy than full noun phrases (Thompson 1990), the frequency of non-overt arguments suggests that agent is most topic-worthy followed by goal and patient.

Because of the high frequency of non-overt arguments, the number of clauses that contain both goal NPs and patient NPs is small. There were only two clauses in conversation and 50 clauses in written data.

Table 1: frequency of each of seven verbs

\begin{tabular}{|c|c|c|c|}
\hline & English equivalent & Written & Conversation \\
\hline ageru & give & 11 & 4 \\
\hline ataeru & give & 39 & 0 \\
\hline azukeru & entrust & 10 & 0 \\
\hline dasu & put out & 1 & 2 \\
\hline kaesu & return & 14 & 1 \\
\hline okuru & send & 13 & 6 \\
\hline todokeru & deliver & 9 & 0 \\
\hline Total & & 97 & 13 \\
\hline
\end{tabular}

Table 1 shows the frequency of each verb in the data. The primary difference between the two types of corpora was that the verb ataeru occurred only in the written data and was the most frequent in the written data.

\subsection{Frequency of Goal-Patient vs. Patient-Goal}

Obviously, the data that are relevant for the examination of word order are the 50 clauses that contain both goal NPs and patient NPs. The two instances observed in the conversation data consist of one each of goal-patient and patient-goal as shown in (12a-b).

(12) a. (from Japanese Corpus, "Yoyaku")

$\begin{array}{llll}\text { sore-o anata-ni } & \text { okur-u }-u \quad \text { kara. } \\ \text { that-ACC you-GOAL } & \text { send-NONPAST FP } \\ \text { 'I am sending that to you.' } & \end{array}$

\footnotetext{
${ }^{4}$ Four clauses were irrelevant in the examination of whether or not an agent is overtly expressed: two in request forms, and two in relative clauses whose heads were agents.
} 
b. (from Japanese Corpus, "Saikin no ko")

sono tyuuzaiin-no ozyosan-ni

that overseas employee-GEN daughter-GOAL

$\begin{array}{llll}\text { Hikarugenzi-no syasin-o okut-te } & \text { age-ru } \\ \text { Hikarugenji-GEN } & \text { photo-ACC } & \text { send-GER } & \text { give-NONPAST } \\ \text { '(I'll) send Hikarugenji's photos to that overseas employee's daughter.' }\end{array}$

We distinguished between two types of written data: narrative and conversation. Because the writers imitate conversations in the latter, its characteristics may diverge from those of written narratives. There were 45 instances of dative clauses containing both goal NPs and patient NPs in the narrative portions, and 5 instances in the conversational portions. The former consists of 32 goal-patient clauses and 13 patient-goal clauses; the latter consists of 2 goal-patient clauses and 3 patient-goal clauses.

In sum, although there were some occurrences of patient-goal orders in all three types of data (i.e., conversation, conversational portion and narratives in written data), the canonical order clauses were found to be much more frequent. Thus, the canonical order prevails over the iconic patient-goal order. But a question arises whether the frequent occurrence of goal-patient order is merely due to the fact that it is a canonical order, or is due to factors that contribute to topic-worthiness. We will now look at each of the factors.

\subsection{Referentiality}

Because the numbers of dative clauses occurring with overtly mentioned goal and patient are too small in the conversational data and written quotes data, we will hereafter discuss the results from the narrative portions only.

In order to examine the effect of referentiality, each NP was first coded as referential or non-referential. Then, word orders of goal and patient NPs were counted for three types of referential status of the two NPs: 1) the referential status of two NPs are equal (i.e., both NPs are referential, or both NPs were nonreferential); 2) goal NP is referential but patient NP is not; and 3) patient NP is referential but goal NP is not. Table 2 shows the results.

Table 2:

\begin{tabular}{|l|l|l|}
\hline Referentiality & Goal-Patient & Patient-Goal \\
\hline Goal $=$ Patient & $67 \%(12 / 18)$ & $33 \%(6 / 18)$ \\
\hline Goal $>$ Patient & $80 \%(20 / 25)$ & $20 \%(5 / 25)$ \\
\hline Goal < Patient & $0 \%(0 / 2)$ & $100 \%(2 / 2)$ \\
\hline
\end{tabular}

Clearly, there is a tendency that referential NPs precede non-referential NPs. When goal is referential and patient is not (i.e., "Goal>Patient"), it is more likely for goal to precede patient than when goal and patient have equivalent referential status. This is compatible with what Thompson (1990) found: goal is more topicworthy than patient, and referentiality being one of the criteria for topic- 
worthiness, goal is likely to be more referential than patient. There were only two instances in which patient is referential when goal is not; in both cases, the word order was non-canonical patient-goal.

\subsection{Animacy}

Each NP was coded for animacy status (i.e., "A" for animate or "I" for inanimate). Table 3 demonstrates how the animacy statuses of NPs affect the word order of dative constructions in discourse.

Table 3:

\begin{tabular}{|l|l|l|}
\hline Animacy & Goal-Patient & Patient-Goal \\
\hline Goal(A) $=$ Patient(A) & $100 \%(3 / 3)$ & $0 \%(0 / 3)$ \\
\hline Goal(I) = Patient (I) & $29 \%(2 / 7)$ & $71 \%(5 / 7)$ \\
\hline Goal(A) > Patient (I) & $79 \%(26 / 33)$ & $21 \%(7 / 33)$ \\
\hline Goal(I) $<$ Patient(A) & $50 \%(1 / 2)$ & $50 \%(1 / 2)$ \\
\hline
\end{tabular}

We see a general tendency that an animate NP is more likely to precede an inanimate NP. Although the numbers are very small, the canonical word order (goal-patient) appears to be preferred when both goal and patient are animate, while preference is not observed when patient is animate and goal is not.

\subsection{Heaviness}

Each NP was coded as 'heavy' when it has a modifier of any length. The relationship between the heaviness of NPs and the word order of sentences is indicated in Table 4:

Table 4:

\begin{tabular}{|l|l|l|}
\hline Heaviness & Goal-Patient & Patient-Goal \\
\hline Goal = Patient & $85 \%(17 / 20)$ & $15 \%(3 / 20)$ \\
\hline Goal > Patient & $61 \%(11 / 18)$ & $39 \%(7 / 18)$ \\
\hline Goal < Patient & $57 \%(4 / 7)$ & $43 \%(3 / 7)$ \\
\hline
\end{tabular}

Heavy NPs are more likely to precede NPs without modifiers in our data. When the heaviness of Goal and Patient NPs are equal, the canonical goal-patient is preferred. This is in accord to Yamashita's (2002) finding.

\subsection{Accessibility}

The accessibility of each NP was coded as Given, Inferable, or New. The older the information that an NP represents is, the higher accessibility it has. In Table 5, "Goal > Patient" indicates that the referent of goal NP is older than patient (e.g. goal NP is given or inferable when patient NP is new). 
Table 5:

\begin{tabular}{|l|l|l|}
\hline Accessibility & Goal-Patient & Patient-Goal \\
\hline Goal $=$ Patient & $65 \%(11 / 17)$ & $35 \%(6 / 17)$ \\
\hline Goal $>$ Patient & $83 \%(20 / 24)$ & $17 \%(4 / 24)$ \\
\hline Goal $<$ Patient & $25 \%(1 / 4)$ & $75 \%(3 / 4)$ \\
\hline
\end{tabular}

When goal NP is more accessible than patient NP, goal-patient order is more frequent than in cases in which the information statuses of goal and patient are equivalent. Moreover, although the number of cases in which patient NP is more accessible is very small, in these cases, patient-goal order seems to be preferred. Thus, in our data, more accessible NPs tend to precede NPs referring to newer information.

\section{Conclusions}

We first found that the spoken corpus and the conversational portion of the written corpus had very few instances of dative clauses in which both patient and goal are overtly expressed. Thus our analysis focused on the written corpus.

In the written corpus, canonical goal-patient order was the predominant word order of NPs in dative clauses. The goal-patient order may be selected because viewpoint is on the goal NP due to its topic-worthiness measured by such factors as referentiality, animacy, and accessibility. Goal NPs tended to be referential, animate, heavy and accessible.

In the few instances in which patient has topic-worthy characteristics, the preference for the goal-patient order seemed to disappear. In other words, the dative clauses resulted in iconic patient-goal order when patient was topic-worthy, especially when goal is inanimate. However, the number of such instances is too small for us to submit the results to statistical testing or to make any conclusive statement.

In the current study, the topic-worthiness of NPs was considered separately for each factor; however, the factors may have additive effects (e.g., a referential animate NP may be more topic-worthy than a non-referential animate NP). Hence, in future investigation on the role of iconicity, it may be beneficial to examine a number of cases in which patient and goal can be considered as roughly equally topic-worthy considering the multiple factors.

\section{References}

Aoki, Hiromi, Yuka Matsugu, Mizuki Miyashita, Tsuyoshi Ono, and Misumi Sadler. To appear. Japanese Corpus. Department of East Asian Studies, University of Arizona.

Bresnan, Joan, and Tatiana Nikitina. 2003. On the gradience of the dative alternation. Ms., Stanford University. 
Cho, Sookeun, Miseon Lee, William O'Grady, Minsun Song, Takaaki Suzuki, and Naoko Yoshinaga. 2002. Word order preferences for direct and indirect objects in children learning Korean. Journal of Child Language 29: 897-909.

Collins, Peter. 1995. The indirect object construction in English: An informational approach. Linguistics 33: 35-49.

DeLancey, Scott. 1981. An interpretation of split ergativity and related patterns. Language 57(3): 626-657.

Ferreira, Victor S., and Hiromi Yoshita. 2003. Given-new ordering effects on the production of scrambled sentences in Japanese. Journal of Psycholinguistic Research 32(6): 669-692.

Givón, T. 1984. Direct object and dative shifting: Semantic and pragmatic case. In F. Plank (ed.) Objects: Towards a Theory of Grammatical Relations, 151-182. London: Academic Press.

Givón, T. 1995. Isomorphism in the grammatical code. In R. Simone (ed.) Iconicity in Language, 47-76. Amsterdam: John Benjamins.

Haiman, John. 1980. The iconicity of grammar: Isomorphism and motivation. Language 56(3): 515-540.

Hoji, Hajime. 1985. Logical form constraints and configurational structures in Japanese. Ph.D. dissertation, University of Washington.

Kabata, Kaori. 2000. Japanese ni: A cognitive analysis of a lexically complex particle. Ph.D. dissertation, University of Alberta.

Kawano, Yasuko. 2004. Kukan hyogen ni okeru kakuseibun no gojun [On the relative order of ni- and o-phrases in spatial expressions]. Nihongo Kyoiku 120: 23-30.

Miyagawa, Shigeru. 1997. Against optional scrambling. Linguistic Inquiry 28: $1-26$.

Miyagawa, Shigeru, and Takae Tsujioka. 2004. Argument structure and ditransitive verbs in Japanese. Journal of East Asian Linguistics 13(1): 1-38.

Shinchosha Publisher. 2000. Shinchosha no zeppan 100-satsu. [100 out of print books from Shinchosha Publisher] CD-ROM.

Sadakane, Kumi, and Masatoshi Koizumi. 1995. On the nature of the "dative" particle $n i$ in Japanese. Linguistics 33: 5-33.

Smyth, Ronald H., Gary D. Prideaux, and John T. Hogan. 1979. The effect of context on dative position. Lingua 47: 27-42.

Sugisaki, Koji, and Miwa Isobe. 2001. What can child Japanese tell us about the syntax of scrambling? In K. Megerdoomian and L.A. Bar-el (eds.) WCCFL 20 Proceedings, 538-551.

Suzuki, Takaaki, Sookeum Cho, Miseon Lee, William O'Grady, Minsun Song, and Naoko Yoshinaga. 1999. Word order preference for direct and indirect objects in children learning Japanese. The $2^{\text {nd }}$ International Conference on Cognitive Science and The $16^{\text {th }}$ Annual Meeting of the Japanese Cognitive Science Society Joint Conference, 108-112. 
Thompson, Sandra. A. 1990. Information flow and dative shift in English discourse. In J.A. Edmondson, C. Feagin, and P. Muhlhausler (eds.) Development and Diversity: Language Variation Across Time and Space, 239-253. Dallas, TX: Summer Institute of Linguistics, University of Texas at Arlington.

Thompson, Sandra. A. 1995. The iconicity of "dative shift" in English: Considerations from information flow in discourse. In M. E. Landsberg (ed.) Syntactic Iconicity and Linguistic Freezes: The Human Dimension, 155-175. Berlin/New York: Mouton de Gruyter.

Thompson, Sandra. A., and Yuka Koide. 1987. Iconicity and 'indirect objects' in English. Journal of Pragmatics 11: 399-406.

Wierzbicka, Anna. 1986. The semantics of 'internal dative' in English. Quaderni di Semantica 7(1): 121-135.

Yamashita, Hiroko. 2002. Scrambled sentences in Japanese: Linguistic properties and motivations for production. Text 22(4): 597-633.

Yamashita, Hiroko, Yuki Hirose, and Franklin Chang. 2003. The nature of grammatical coding: Syntactic-independent formation of a constituent structure. Poster presented at the 20th Japanese Cognitive Science Society meeting. The University of Electro-Communications.

Yatsushiro, Kazuko. 2003. VP internal scrambling. Journal of East Asian Linguistics 12: 141-170.

Noriko Iwasaki

EALC

University of California Davis

One Shields Avenue

Davis, CA 95616

niwasaki@ucdavis.edu
Misumi Sadler

EALC

University of Illinois Urbana-Champaign

FLB 2090, 707 Mathews

Champaign, IL 61801

sadlerm@uiuc.edu 